\title{
ORGANIZATIONAL, ETHICAL AND LEGAL ASPECTS OF PALLIATIVE CARE IN ALBANIA
}

\author{
Andia Meksi ${ }^{1}$, Enkelejda Shkurti ${ }^{*}$ \\ ${ }^{1}$ Institute of Public Health, Tirana, Albania; \\ ${ }^{2 *}$ University of Medicine, Tirana, Albania;
}

"Corresponding Author Enkelejda Shkurti, e-mail: enkeleda.shkurti@umed.edu.al;

Received November 2021; Accepted December 2021; Published January 2022;

DOI: https://doi.org/10.31407/ijees12.115

\begin{abstract}
Palliative care is a fundamental human right. The absence and limitation of palliative care provision to those who need it would not be ethical when there are effective affordable methods. Palliative care services in Albania face major challenges. Some of these challenges are being addressed, including the work being done by some donation and state-based organizations. There is a need for greater investments in health and palliative care services and focusing on patient rights will be a priority in the future. In general, palliative care services in Albania are scarce and fragmented. It should be noted that palliative care is not sufficiently integrated into the public health care system. In Albania, palliative care is mainly considered as a palliative oncology service. In this perspective, a national palliative care policy and strategy is needed to create access for all terminal patients, including cancer but also advanced chronic diseases for the elderly, children and adolescents and people living with HIV and AIDS. Also, special attention is paid to the application of ethical principles in the practical activity of Palliative Care services in Albania.
\end{abstract}

Keywords: palliative care, oncology service, Albania. 